\title{
PENDAMPINGAN PERENCANAAN DAN PENGANGGARAN RESPONSIF GENDER DI KANTOR KEMENTRIAN AGAMA KABUPATEN TULUNGAGUNG
}

\author{
Dwi Sulistiani \\ dwisulistiani@pips.uin-malang.ac.id \\ UIN Maulana Malik Ibrahim Malang
}

\begin{abstract}
This research was conducted at the Ministry of Religion district Tulungagung related to the preparation of PPRG documents using PAR (Partisipatory Action Research) method. The purpose of this study is to provide assistance in the preparation of PPRG documents consisting of GAP and GBS at the Ministry of Religion district Tulungagung. In addition, to find out how far their understanding related to PPRG. Assistance related to the preparation of PPRG in the form of documents GAP and GBS is very necessary by the Office of Ministry of Religious Affairs, especially in Tulungagung which is difficult in preparing the document. With the appeal from the Ministry of Religious Affairs to the satker below to prepare the PPRG documents, the Ministry of Religious Affairs in the districts should also contribute to the success of the program. The results of this PPRG assistance is the establishment of 7 GAP and 7 GBS documents prepared in 2017 to become a document companion for the fiscal year 2018. Based on observations at the time of socialization and mentoring proved that planners at the Ministry of Religion district Tulungagung still do not understand PPRG and still difficult in the preparation the document. Subsequent research could take other assisted objects and also add activity strategies with monitoring and evaluation in the implementation of PPRG in satker under the ministry of religion or other ministries.
\end{abstract}

Keywords: PAR, PPRG, GAP, GBS

\section{Abstrak}

Penelitian ini dilakukan di Kementerian Agama kabupaten Tulungagung terkait dengan persiapan dokumen PPRG menggunakan metode PAR (Partisipatory Action Research). Tujuan dari penelitian ini adalah untuk memberikan bantuan dalam penyusunan dokumen PPRG yang terdiri dari GAP dan GBS di Kementerian Agama kabupaten Tulungagung. Selain itu, untuk mengetahui sejauh mana pemahaman mereka terkait dengan PPRG. Bantuan terkait persiapan PPRG dalam bentuk dokumen GAP dan GBS sangat diperlukan oleh Kantor Kementerian Agama, khususnya di Tulungagung yang kesulitan dalam menyiapkan dokumen. Dengan seruan dari Kementerian Agama kepada satker di bawah ini untuk menyiapkan dokumen PPRG, Kementerian Agama di kabupaten juga harus berkontribusi pada keberhasilan program. Hasil dari bantuan PPRG ini adalah pembentukan 7 dokumen GAP dan 7 GBS yang disiapkan pada tahun 2017 untuk menjadi dokumen pendamping untuk tahun fiskal 2018. Berdasarkan pengamatan pada saat sosialisasi dan pendampingan terbukti bahwa perencana di Kementerian Agama kabupaten Tulungagung masih belum mengerti PPRG dan masih kesulitan dalam persiapan dokumen. Penelitian selanjutnya dapat

$$
\sim 14 \sim
$$


mengambil objek bantuan lainnya dan juga menambahkan strategi kegiatan dengan pemantauan dan evaluasi dalam pelaksanaan PPRG di satker di bawah kementerian agama atau kementerian lain.

Kata kunci: PAR, PPRG, GAP, GBS

\section{PENDAHULUAN}

Berbicara masalah peningkatan mutu pendidikan agama dan keagamaan yang menjadi fokus perhatian Kementerian Agama, tidak dapat dipungkiri bahwa pembangunan bidang pendidikan Islam merupakan sektor pembangunan yang paling besar dan luas cakupannya. Hal ini tidak lain karena lebih dari 87\% penduduk Indonesia memeluk agama Islam (Badan Pusat Statistik, 2010). Atas dasar inilah dibentuk sebuah unit kerja Eselon I di lingkungan Kementerian Agama yang diamanati untuk memberikan pelayanan pendidikan agama dan keagamaan Islam, yakni Direktorat Jenderal Pendidikan Islam.

Sadar akan keragaman kebutuhan dan kondisi perempuan dan laki-laki, penerapan kebijakan pengarusutamaan gender (PUG) menjadi pilihan pemerintah untuk menerapkan pembangunan nasional yang berkeadilan. PUG telah dicanangkan sebagai salah satu dari tiga strategi nasional dalam Rencana Pembangunan Jangka Menengah Nasional (RPJMN) Tahun 20102014. RPJMN secara tegas telah mengintegrasikan kebijakan PUG dalam sistem perencanaan dan penganggaran. Melalui pengintegrasian PUG dalam perencanaan dan penganggaran, program/kegiatan yang dibuat akan menjadi responsif gender. Oleh karenanya, Perencanaan dan Penganggaran Responsif Gender (PPRG) bukanlah suatu proses yang terpisah dari sistem perencanaan dan penganggaran yang ada, namun justru akan menguatkan pencapaian tujuan pembangunan nasional yang berkeadilan. Aturan terkait pelaksanaan PPRG sudah diatur dalam beberapa peraturan menteri baik menteri keuangan maupun menteri agama berikut ini:

a. Peraturan Menteri Agama RI Nomor 11 Tahun 2006 Tentang Penetapan Unit Pelaksana, Tugas dan Fungsi Pengarusutamaan Gender di Lingkungan Departemen Agama (Indonesia. Kementerian Agama, 2006)

b. Peraturan Menteri Agama Republik Indonesia Nomor 17 tahun 2010 Tentang Pemberian Beasiswa Responsof Gender Bagi siswa Madrasah Perguruan Tinggi Agama dari Keluarga Miskin di Lingkungan Kementerian Agama (Indonesia. Kementerian Agama, 2010)

c. Kesepakatan bersama antara Kementerian pemberdayaan perempuan dan perlindungan Anak Republik Indonesia Nomor 02 tahun 2011 Tentang Pelaksanaan Pengarusutamaan Gender dan Pemenuhan Hak Anak di bidang Keagamaan (Indonesia. Kementerian Pemberdayaan Perempuan dan Perlindungan Anak \& Indonesia. Kementerian Agama, 2011) 
d. Peraturan Menteri Keuangan Nomor 136/ PMK.02/2014 tanggal 11 Juli 2014 tentang Petunjuk Penyususnan dan Penelaahan Rencana Kerja dan Anggaran Kementerian Negara/Lembaga (Indonesia. Kementerian Keuangan, 2014)

Dalam konteks pembangunan bidang pendidikan Islam, pelaksanaan integrasi PUG ke dalam siklus perencanaan dan penganggaran (hingga monitoring dan evaluasi) diharapkan dapat memberikan dampak pembangunan yang lebih efektif, dapat dipertanggungjawabkan, dan adil dalam memberikan manfaat pembangunan, baik bagi kelompok perempuan maupun laki-laki. Melalui PPRG, empat aspek yang terdiri dari akses, partisipasi kontrol, dan manfaat akan menjadi salah satu fokus dalam analisis gender. Dengan dilakukan analisis gender, diharapkan dapat mengakomodasi aspirasi, kebutuhan, dan permasalahan perempuan dan laki-laki secara tepat dan seksama. Tujuan penelitian ini adalah untuk memberikan pendampingan dalam penyusunan dokumen PPRG yang terdiri dari GAP dan GBS pada Kantor Kemenag kabupten Tulungagung. Selain itu juga untuk mengetahui seberapa jauh pemahaman mereka terkait PPRG.

\section{METODOLOGI PENELITIAN}

Penelitian ini menggunakan metode PAR (Participatory Action Research). Langkah-Langkah dalam Pendampingan terdapat 4 tahapan, yatu:

1. Perencanaan (plan). Perencanaan ini dilkaukan setelah memperhatikan kondisi riil objek dampingan, dimana di Kemenag Kabupaten Tulungagung masih belum menyusun dokumen PPRG sehingga perlu untuk dilakukan sosialisasi dan pendampingan terkait hal tersebut. Analisis SWOT adalah suatu alat perencanaan strategik yang penting untuk membantu perencana untuk membandingkan kekuatan dan kelemahan internal organisasi dengan kesempatan dan ancaman dari external, yaitu dengan analisis SWOT.

\section{SWOT Analysis}

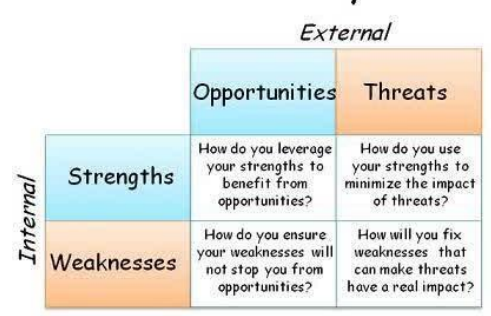

Pada analisis SWOT memberikan informasi untuk membantu dalam hal mencocokan perusahaan sumber daya dan kemampuan untuk menganalisa kompetitif lingkungan di mana bidang perusahaan itu bergerak. Informasi tersebut dibuat berdasarkan perumusan strategi dan seleksi.

2. Tindakan (Action). Setelah proses perencanaan dilakukan, pegawai di Kankemenag Kabupaten Tulungagung khususnya bagian perencanaan mendapatkan sosialisasi dan pendampingan dari fasilitator

$$
\sim 16 \sim
$$


3. Pengamatan (Observe). Pengamatan dilakukan untuk memperhatikan dan menganalisis keberhasilan, kelemehan, dan kekurangan strategi dan metode yang digunakan dalma menyelesaikan masalah-masalah terkait PPRG di Kankemenag Kabupaten Tulungagung. Demikian pula faktor-faktor pendukung dan hambatan yang teridentifikasi selama keiatan berlangsung

4. Refleksi (reflect). Usaha-usaha yang telah dilakukan dalam memecahkan masalah-masalah terkait PPRG di Kankemenag Kabupaten Tulungagung tersebut direfleksikan dan dievaluasi, baik kekurangan, kelemahan, keberhasilan strategi dan metode dalam memecahkan masalah-masalah tersebut. Refleksi dan evaluasi ini akan berputar terus menuju tapahan yang pertama yaitu perencanaan (plan).

Strategi yang dilakukan untuk mencapai kondisi yang diharapkan adalah dengan melakukan langkah-langkah sebagai berikut :

1. Melakukan focus group discussion (FGD) untuk mengakomodir permasalahan dan kebutuhan yang diperlukan oleh perencana dan pihak terkait di Kankemenag Kabupaten Tulungagung

2. Melakukan sosialisasi terkait PPRG dan penyusunan dokumennya berupa GAP dan GBS khususnya bagi kepala kantor sebagai penentu kebijakan, sangat penting untuk mengetahuinya

3. Melakukan pendampingan dalam penyusunan GAP dan GBS

4. Mereview dokumen PPRG yang sudah disusun oleh perencana di Kankemenag Kabupaten Tulungagung

\section{PEMBAHASAN}

Perencanaan Responsif Gender (PRG) adalah Perencanaan untuk mencapai kesetaraan dan keadilan Gender, yang di lakukan melalui pengintregasian pengalaman aspirasi, kebutuhan potensi dan penyelesaian permasalahan perempuan dan laki-laki. ARG merupakan Upaya untuk menjamin agar anggaran yang dikeluarkan oleh pemerintah beserta kebijakan dan program yang mendasarinya dilaksanakan untuk menjawab kebutuhan setiap warga negara dari kelompok manapun, baik laki-laki maupun perempuan. Merupakan anggaran yang disusun dan disyahkan melalui proses analisis dalam perspektif gender. Tujuan ARG adalah:

1. Akuntabilitas anggaran berdampak gender

2. Mengubah alokasi anggaran \& program utk meningkatkan kesetaraan gender

3. Meningkatkan kesadaran isu dan program responsif gender Perencanaan yang responsif gender dilakukan dengan memasukkan perbedaan pengalaman, aspirasi, kebutuhan, dan permasalahan perempuan dan laki-laki dalam proses penyusunan kebijakan dan 
program pembangunan daerah. Hal tersebut bisa mempertajam analisis tentang kondisi daerah karena terpetakan kesejangan dalam pembangunan manusia, laki-laki dan perempuan, serta membantu mempertajam target group/ kelompok sasaran karena data terpilah.

PPRG tidak selalu berupa penambahan program baru dan biaya tambahan bilamana analisis gender diterapkan. Pemberdayaan perempuan sebagai urusan wajib di daerah tidak mampu menjawab semua isu kesenjangan gender di berbagai bidang. Prinsip PPRG adalah sebagai berikut:

1. Syarat utama untuk melaksanakan PPRG adalah kemauan politik dan komitmen dari pembuat kebijakan publik.

2. Penerapan PPRG fokus pada program \& kebijakan dalam rangka: 1) penugasan prioritas pembangunan daerah yang mendukung prioritas pembangunan nasional dan pencapaian SDG's; 2) pelayanan kepada masyarakat (service delivery) berdasarkan pencapaian SPM; dan/atau 3) pencapaian visidan misi kemeterian agama.

3. ARG bukan fokus pada perencanaan dan penyediaan anggaran dengan jumlah tertentu untuk PUG saja, tapi lebih luas lagi, agar perencanaan \& anggaran keseluruhan dapat memberikan manfaat yang adil bagi perempuan \& laki-laki baik sebagai penerima manfaat maupun pelaku pembangunan

Dalam melakukan keseluruhan proses perencanaan kebijakan maupun perencanaan program pembangunan agar responsif gender (terrmasuk perencanaan kegiatan pembangunan), diperlukan piranti analisis gender. Salah satu alat analisis gender adalah "Gender Analysis Pathway" (GAP), atau Alur Kerja Analisis Gender. Gender Analysis Pathway (GAP) adalah suatu alat analisis gender yang dapat digunakan untuk membantu para perencana dalam melakukan pengarusutamaan gender dalam perencanaan kebijakan/ program/ kegiatan pembangunan. Dengan menggunakan GAP, para perencana kebijakan/program/kegiatan pembangunan dapat mengidentifikasi kesenjangan gender (gender GAP) dan permasalahan gender (gender issues) serta sekaligus menyusun rencana kebijakan/program/ kegiatan pembangunan yang ditujukan untuk memperkecil atau menghapus kesenjangan gender tersebut. (Indonesia. Badan Perencanaan Pembangunan Nasional, 2001). Tujuan GAP adalah:

1. Membantu perencana dalam menyusun perencanaan program responsif gender

2. Mengidentifikasi kesenjangan gender (peran, akses, kontrol dan manfaat yang diperoleh).

3. Mengetahui latar belakang terjadinya kesenjangan gender

4. Merumuskan permasalahan sebagai akibat adanya kesenjangan gender.

5. Mengidentifikasi langkah-langkah/ tindakan intervensi yang diperlukan. 
Dalam penyusunan GAP diperlukan langkah-langkah dan matrik sebagai berikut:

Tabel 1. Langkah-Langkah GAP

\begin{tabular}{|c|c|}
\hline Langkah- langkah GAP & Penjelasan \\
\hline $\begin{array}{l}\text { 1. Pilih } \\
\text { Kebijakan/ Program/ } \\
\text { Kegiatan yang akan } \\
\text { dianalisis }\end{array}$ & $\begin{array}{l}\text { Memilih kebijakan/program/kegiatan yang hendak } \\
\text { dianalisis } \\
\text { Menuliskan } \\
\text { kebijakan/program/kegiatan }\end{array}$ \\
\hline $\begin{array}{l}\text { 2. Menyajikan data Pembuka } \\
\text { Wawasan }\end{array}$ & $\begin{array}{l}\text { Menyajikan data pembuka wawasan yang terpilah } \\
\text { menurut jenis kelamin } \\
\text { Data terpilah ini bisa berupa data statistik yang } \\
\text { kuantitatif atau kualitatif, misal: hasil survei, hasil } \\
\text { FGD, review pustaka, hasil kajaian, hasil } \\
\text { pengamatan, atau hasil intervensi } \\
\text { kebijakan/program/kegiatan yang sedang dilakukan }\end{array}$ \\
\hline $\begin{array}{l}\text { 3. Mengenali faktor } \\
\text { kesenjangan gender }\end{array}$ & $\begin{array}{l}\text { Menemukenali dan mengetahui ada tidaknyaa faktor } \\
\text { kesenjangan gender, yaitu: akses, partisipasi, kontrol } \\
\text { dan manfaat (APKM) }\end{array}$ \\
\hline $\begin{array}{l}\text { 4. Menemukenali sebab } \\
\text { kesenjangan internal }\end{array}$ & $\begin{array}{l}\text { Temu kenali isu gender di internal lembaga. } \\
\text { Misalnya: terkait dengan produk hukum, kebijakan, } \\
\text { pemahaman yang masih kurang diantara pengambil } \\
\text { keputusan dalam internal lembaga }\end{array}$ \\
\hline $\begin{array}{l}\text { 5. Menemukenali sebab } \\
\text { kesenjangan eksternal }\end{array}$ & 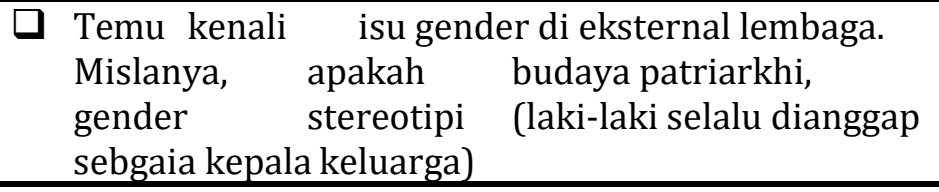 \\
\hline 6. Reformulasi tujuan & $\begin{array}{lll}\text { Menrumuskan } & \text { kembali } & \text { tujuan } \\
\text { kebijakan/program/kegiatan yangresponsif gender }\end{array}$ \\
\hline 7. Rencana Aksi & $\begin{array}{l}\text { Menetapkan rencana aksi } \\
\text { Rencana aksi diharapkan mengatasi kesenjangan } \\
\text { gender yang teridentifikasi pada langkah } 3,4 \text { dan } 5\end{array}$ \\
\hline 8. Data dasar & $\begin{array}{l}\text { Menetapkan data dasar yang dipilih untuk } \\
\text { mengukur kemajuan (progress) } \\
\text { Data yang dimaksud diambil dari data pembuka } \\
\text { wawasan yaang telah diungkapkan padaa langkah } 2 \\
\text { yang terkait dengan tujuan kegiatan dan output } \\
\text { kegiatan }\end{array}$ \\
\hline 9. Indikator gender & $\begin{array}{l}\text { Menetapkan indikator gender sebagai pengukuran } \\
\text { hasil melalui ukuran kuantitatif maupun kualitatif }\end{array}$ \\
\hline
\end{tabular}


GBS adalah dokumen yang menginformasikan suatu kegiatan telah responsif terhadap isu gender yang ada dan apakah telah dialokasikan dana pada kegiatan bersangkutan. GBS disusun pada saat persiapan RKA SKPD. Peluang integrasi gender akan lebih mantap kalau GBS lebih awal disiapkan. Data GBS didapat dari hasil pengisian dokumen GAP, berikut ini contoh dokumen GBS :

Tabel 2. Gender Budget Statement

(Pernyataan Anggaran Gender)

Nama SKPD :

Tahun $\quad: \ldots . .$.

\begin{tabular}{|c|c|}
\hline \multicolumn{2}{|l|}{ Program } \\
\hline Tujuan & \\
\hline Capaian Program & Indikator: \\
\hline Kegiatan & \\
\hline Tujuan Kegiatan & \\
\hline Kode Rekening & \\
\hline Analisa situasi & $\begin{array}{l}\text { Data pilah: } \\
\text { Hal ini disebabkan adanya kesenjangan dibidang } \\
: \\
\text { AKSES : PARTISIPASI : } \\
\text { KONTROL : MANFAAT : } \\
\text { Faktor internal : Faktor } \\
\text { eksternal : }\end{array}$ \\
\hline Perencanaan Kegiatan & Kegiatan /Sub kegiatan : \\
\hline & Komponen input: \\
\hline Sumber Dana & \\
\hline $\begin{array}{l}\text { Dampak / Hasil } \\
\text { Output kegiatan }\end{array}$ & $\begin{array}{l}\text { Capaian: } \\
\text { Indikator output : }\end{array}$ \\
\hline
\end{tabular}

\begin{tabular}{|c|c|c|c|c|c|c|c|c|}
\hline \multicolumn{9}{|c|}{ Tabel 3 Matrik Gender Analysis Pathway (GAP) } \\
\hline $\begin{array}{l}\text { Langkah } \\
1\end{array}$ & $\begin{array}{r}\text { Langk } \\
\text { a h } 2\end{array}$ & $\begin{array}{l}\text { Langk } \\
\text { a h } \\
3\end{array}$ & $\begin{array}{l}\text { Langkah } \\
4\end{array}$ & $\begin{array}{l}\text { Langkah } \\
5\end{array}$ & Langkah 6 & Langkah 7 & Langka h 8 & Langkah 9 \\
\hline \multirow[b]{2}{*}{$\begin{array}{c}\text { Nama } \\
\text { Kebijaka } \\
\text { n/ } \\
\text { Program } \\
\text { /Kegi } \\
\text { atan }\end{array}$} & \multirow[b]{2}{*}{$\begin{array}{c}\text { Data } \\
\text { Pemb } \\
\text { uk a } \\
\text { Wawa } \\
s \text { an }\end{array}$} & \multicolumn{3}{|c|}{ Isu Gender } & \multicolumn{2}{|c|}{$\begin{array}{l}\text { Kebijakan dan } \\
\text { Rencana Kedepan } \\
\end{array}$} & \multicolumn{2}{|c|}{ Pengukuran Hasil } \\
\hline & & $\begin{array}{c}\text { Fakto } \\
r \\
\text { Kesen } \\
\text { jang } \\
\text { an }\end{array}$ & $\begin{array}{c}\text { Sebab } \\
\text { Kesenj } \\
\text { a ngan } \\
\text { Intern } \\
\text { al }\end{array}$ & $\begin{array}{c}\text { Sebab } \\
\text { Kesenja } \\
\text { ngan } \\
\text { Ekstern } \\
\text { a l }\end{array}$ & $\begin{array}{l}\text { Reformu } \\
\text { lasi } \\
\text { Tujuan }\end{array}$ & $\begin{array}{l}\text { Rencana } \\
\text { Aksi }\end{array}$ & $\begin{array}{l}\text { Basis Data } \\
\text { (Base- line) }\end{array}$ & $\begin{array}{l}\text { Indikator } \\
\text { Kinerja }\end{array}$ \\
\hline $\begin{array}{l}\text { Tdentifika } \\
\text { si } \\
\text { dan } \\
\text { tuliskan }\end{array}$ & $\begin{array}{l}\text { Sajika } \\
\text { n } \\
\text { data }\end{array}$ & $\begin{array}{l}\text { Temu } \\
\text { kenali } \\
\text { isu }\end{array}$ & $\begin{array}{l}\text { Temu } \\
\text { kenali }\end{array}$ & $\begin{array}{l}\text { Temu } \\
\text { kenali }\end{array}$ & $\begin{array}{l}\text { Reformul } \\
\text { a } \\
\text { si-kan }\end{array}$ & $\begin{array}{l}\text { Tetapkan } \\
\text { rencana }\end{array}$ & $\begin{array}{l}\text { Tetapk } \\
\text { an }\end{array}$ & $\begin{array}{l}\text { Tetapkan } \\
\text { indikator }\end{array}$ \\
\hline
\end{tabular}




\begin{tabular}{|c|c|c|c|c|c|c|c|c|}
\hline $\begin{array}{l}\text { tujuan } \\
\text { dari } \\
\text { Kebijakan } \\
\text { Program/ } \\
\text { Ke } \\
\text { giatan }\end{array}$ & \begin{tabular}{|l} 
pembu \\
k \\
a \\
\\
wawas \\
a \\
n, yang \\
\\
terpila \\
jenis \\
kelami \\
nan \\
dan \\
usia, \\
kuantit \\
a \\
tif dan \\
kualita \\
tif
\end{tabular} & \begin{tabular}{|l} 
gender \\
proses \\
perenc \\
ana \\
an \\
denga \\
n \\
memp \\
erha \\
ti kan \\
faktor- \\
faktor \\
kesenj \\
ang \\
an \\
akses, \\
partisi \\
pasi, \\
kontro \\
ldan \\
manfa \\
at \\
(cantu \\
mka \\
n \\
hanya \\
faktor \\
kesenj \\
ang \\
an \\
yang \\
releva \\
n).
\end{tabular} & \begin{tabular}{|l} 
penyeba \\
faktor \\
faker \\
kesenjan \\
g \\
an \\
gender \\
yang \\
datang \\
dari \\
internal \\
pelaksan \\
a \\
program. \\
\end{tabular} & \begin{tabular}{|l} 
penyeba \\
b faktor \\
kesenja \\
ngan \\
gender \\
yang \\
datang \\
dari \\
lingkung \\
an \\
eksterna \\
l \\
lembaga \\
pada \\
proses \\
pelaksa \\
na an \\
rogram.
\end{tabular} & $\begin{array}{l}\text { tujuan } \\
\text { kebijakan } \\
\text { bila } \\
\text { tujuan } \\
\text { yang ada } \\
\text { saat ini } \\
\text { belum } \\
\text { responsif } \\
\text { gender. } \\
\text { Tujuan ini } \\
\text { harus } \\
\text { menjawab } \\
\text { sebab } \\
\text { kesenjang } \\
\text { an yang di } \\
\text { identifika } \\
\text { si di } \\
\text { langkah } \\
3,4, \text { dan } \\
5 .\end{array}$ & \begin{tabular}{|l|} 
aksi/kegiat \\
an yang \\
merujuk \\
pada \\
tujuan \\
yang \\
responsif \\
gender \\
untuk \\
mengatasi \\
kesenjang \\
an dan \\
penyebabn \\
ya yang \\
ada di \\
langkah 3, \\
4, dan 5. \\
Tetapkan \\
juga \\
rencana \\
aksi \\
prioritas \\
berikut \\
output dan \\
hasil \\
kegiatan.
\end{tabular} & $\begin{array}{l}\text { base- } \\
\text { line } \\
\text { yang } \\
\text { diambil } \\
\text { dari } \\
\text { data } \\
\text { pembu } \\
\text { ka } \\
\text { wawas } \\
\text { an } \\
\text { pada } \\
\text { langka } \\
\text { h } 2 \\
\text { yang } \\
\text { relevan } \\
\text { dengan } \\
\text { tujuan } \\
\text { dan } \\
\text { dapat } \\
\text { diukur. }\end{array}$ & $\begin{array}{l}\text { kinerja } \\
\text { (baik } \\
\text { capaian } \\
\text { output } \\
\text { maupun } \\
\text { outcome) } \\
\text { yang } \\
\text { mengatasi } \\
\text { kesenjang } \\
\text { an gender } \\
\text { di langkah } \\
3,4, \text { dan } \\
5 .\end{array}$ \\
\hline
\end{tabular}

\section{HASIL YANG DICAPAI}

Berdasarkan FGD yang dilakukan, Kankemenag Kabupeten Tulungagung memang memerlukan pendampingan terkait penyusunan dokumen PPRG apalagi hal tersebut merupakan himbauan dari Kementrian Agama agar satker dibawahnya menyusun dokumen PPRG yang menjadi dokumen pendukung dalam anggaran yang diajukan. Setelah dilakukan FGD, sosialisasi terkait PPRG dilakukan dengan dihadiri oleh Kepala dan sekretaris kantor kemenag Tulungagung beserta perencana yang terkait langsung dengan PPRG. Dalam sosialisasi yang dilakukan terlihat bahwa pemahaman peserta sosialisasi terkait PPRG masih belum tinggi, hal tersebut terbukti dengan ketidaktahuan mereka apa itu PPRG dan ARG. Sebagian dari mereka bahkan masih bias gender, karena menganggap bahwa laki-laki itu adalah pemimpin bagi perempuan sehingga tidak mungkin akan ada kesetaraan antara laki-laki dan perempuan.Selain itu juga budaya patriarki yang ada di daerah tersebut yang masih kental sehingga perempuanpun sulit untuk menjadi pemimpin karena kesibukannya dirumah tangga dan kesulitan untuk pergi keluar kota dengan alasan anak tidak bisa ditinggal. Perencana juga 
merasa keberatan dengan kewajiban penyusunan dokumen mereka, karena dianggap menambah pekerjaan mereka. Juga terdapat kendala lain yaitu personil perencanaan yang kadang berubah sehingga harus memberikan pengetahuan lagi terkait PPRG. Strategi yang dilakukan oleh fasilitator adalah tidak memperdebatkan lagi terkait konsep gender, tapi lebih fokus pada PPRG yang itu memang sudah menjadi kewajiban tiap satker dibawah Kemenag untuk menjalankan amanah dalam penyusunan dokumen PPRG. Sedangkan terkait kendala sering berubahanya personil perencanaan, fasilitator memberikan materi berupa power point (ppt) yang bisa dipelajari oleh siapapun yang akan menyusun dokumen PPRG.

Selanjutnya dilakukan pendampingan dalam menyusun dokumen PPRG yang diikuti oleh perencana sesuai dengan bidang masing-masing. Para perencana terlihat antusias dalam menyusun dokumen PPRG, kesulitan mereka adalah dalam menyusun dokumen GAP yang itu memang harus memiliki pengalaman tinggi untuk bisa menganalisis kegiatan dengan menggunakan alat analisis tersebut. Tapi dengan pendampingan yang dilakukan kesulitan itu bisa berkurang, sedangkan untuk penyusunan dokumen GBS peserta sudah lebih mudah karena tinggal memindah hasil dari penyusunan dokumen GAP. Pada serangkaian kegiatan ini tersusun 7 dokumen GAP dan 7 dokumen GBS yang mewakili tiap bidang di Kantor Kemenag Kabupaten Tulungagung.

Hasil pendampingan PPRG yang berupa dokumen GAP dan GBS tersebut dibaca lebih jauh lagi oleh fasilitator untuk kemudian direview dan sekaligus direvisi untuk kemudian di serahkan kebali pada perencana Kantor Kemenag Kabupaten Tulungagung agar mereka mengetahui bagaimana menyusun dokumen PPRG yang baik dan benar. Selanjutnya mereka bisa membuat sendiri dokumen PPRG mereka untuk digunakan sebagai dokumen pendamping anggaran mereka.

\section{KESIMPULAN}

Pendampingan terkait penyusunan PPRG yang berupa dokumen GAP dan GBS memang sangat diperlukan oleh Kantor Kemenag khususnya di Tulungagung yang memang kesulitan dalam menyusun dokumen tersebut. Dengan adanya himbauan dari Kementrian Agama pada satker dibawahnya untuk menyusun dokumen PPRG, maka kantor kementrian agama di kabupaten dan kota juga harus ikut andil dalam mensukseskan program tersebut. Hasil dari pendampingan PPRG ini adalah tersusunya 7 dokumen GAP dan 7 GBS yang disusun tahun 2017 untuk menjadi pendamping dokumen bagi tahun anggaran 2018. Berdasarkan pengamatan pada saat sosialisasi dan pendampingan terbukti bahwa perencana di Kantor Kemenag Kabupaten Tulungagung masih belum memahami PPRG dan masih kesulitan dalam penyusunan dokumennya.

Pendampingan dalam penyusunan dokumen PPRG sangat perlu dilakukan pada kantor- 
kantor kemenag lainnya untuk membantu program pemerintah terkait Pengarusutamaan Gender (PUG). Penelitian selanjutnya bisa mengambil objek dampingan lain dan juga menambah strategi kegiatan dengan adanya monitoring dan evaluasi dalam implementasi PPRG di satker di bawah kementrian agama ataupuan kementrian lainnya.

\section{DAFTAR PUSTAKA}

Badan Pusat Statistik. (2010, May). Penduduk Indonesia: Hasil Sensus Penduduk $2010=$ Population of Indonesia: Result of Population Census 2010. Badan Statistik Indonesia, 706. Retrieved from https://www.bps.go.id/

Indonesia. Badan Perencanaan Pembangunan Nasional. (2001). Gender analysis pathway (GAP) : analisis gender untuk perencanaan pembangunan. (Nina Sardjunani, Ed.) (1st ed.). Jakarta: Badan Perencanaan Pembangunan Nasional (Bappenas). Retrieved from http://perpustakaan.bappenas.go.id/lontar/file?file=digital/20527- [_Konten_]-Konten C3687.pdf

Indonesia. Kementerian Agama. Peraturan Menteri Agama Republik Indonesia Nomor 11 Tahun 2006 Tentang Penetapan Unit Pelaksana, Tugas dan Fungsi Pengarusutamaan Gender di Lingkungan Departemen Agama (2006). Retrieved from http://simpuh.kemenag.go.id/regulasi/pma_11_06.pdf

Indonesia. Kementerian Agama. Peraturan Menteri Agama Republik Indonesia Nomor 17 tahun 2010 Tentang Pemberian Beasiswa Responsof Gender Bagi siswa Madrasah Perguruan Tinggi Agama dari Keluarga Miskin di Lingkungan Kementerian Agama (2010). Retrieved from www.djpp.depkumham.go.id

Indonesia. Kementerian Keuangan. Peraturan Menteri Keuangan Nomor 136/ PMK.02/2014 tanggal 11 Juli 2014 tentang Petunjuk Penyususnan dan Penelaahan Rencana Kerja dan Anggaran Kementerian Negara/ Lembaga (2014). Retrieved from http://www.jdih.kemenkeu.go.id/fullText/2014/136 PMK.02 20 14Per.HTM

Indonesia. Kementerian Pemberdayaan Perempuan dan Perlindungan Anak, \& Indonesia. Kementerian Agama. Kesepakatan bersama antara Kementerian pemberdayaan perempuan dan perlindungan Anak Republik Indonesia Nomor 02 tahun 2011 Tentang Pelaksanaan Pengarusutamaan Gender dan Pemenuhan Hak Anak di bidang Keagamaan (2011). 